\title{
Carga viral para citomegalovirus, en líquido de lavado bronquioalveolar, en población pediátrica
}

Aristizabal-Bernal $\mathrm{BH}^{1,2}$, Rincón-Caballero $\mathrm{OL}^{1,2}$, Cano-Romero $\mathrm{MA}^{1}$

Resumen

INTRODUCCIÓN: las infecciones pulmonares son comunes en los pacientes inmunocomprometidos. La carga viral de citomegalovirus se utiliza de rutina para determinar en qué momento se debe iniciar la terapia preventiva en hospederos inmunocomprometidos, diagnosticar enfermedad activa y supervisar la repuesta a una terapia implementada.

OBJETIVO: describir el valor de la carga viral de citomegalovirus en líquido de lavado bronquioalveolar vs. sangre periférica en población pediátrica con signos de infección respiratoria.

MATERIALES Y MÉTODOS: estudio descriptivo, observacional de 16 pacientes pediátricos y 19 episodios, a quienes se les realizó, de manera simultánea, la carga viral de citomegalovirus en sangre y lavado bronquioalveolar.

RESULTADOS Y CONCLUSIONES: todas las cargas virales de citomegalovirus realizadas en lavado bronquioalveolar fueron positivas y en general se obtuvieron valores más elevados que en sangre, lo que sugiere una mayor sensibilidad de la prueba cuando se realiza en este tipo de muestra, en pacientes con sospecha clínica de infección respiratoria por citomegalovirus, lo cual la convierte en una ayuda diagnóstica importante según lo muestran los resultados obtenidos.

PALABRAS CLAVE: infección respiratoria, inmunocomprometidos, citomegalovirus, carga viral, líquido de lavado bronquioalveolar.

Acta Pediatr Mex. 2017 Mar;38(2):91-100.

\section{Cytomegalovirus viral load in bronchoalveolar lavage in the Pediatric population}

Aristizabal-Bernal $\mathrm{BH}^{1,2}$, Rincón-Caballero $\mathrm{OL}^{1,2}$, Cano-Romero $\mathrm{MA}^{1}$

Abstract

INTRODUCTION: Lung infections are common in immunocompromised patients. A routine viral load of cytomegalovirus (CMV) is used
${ }^{1}$ Hospital Pablo Tobon Uribe, HPTU 1.

¿Unidad de Investigación genética molecular, UNIGEM, Colombia.

Recibido: 17 de noviembre del 2015

Aceptado: 7 de septiembre del 2016

Correspondencia

Beatriz Helena Aristizabal

baristizabal@hptu.org.co

beatriz.aristizabal@unigem.com.co

Este artículo debe citarse como Aristizabal-Bernal B H, Rincón-Caballero OL, CanoRomero MA. Carga viral para citomegalovirus, en líquido de lavado bronquioalveolar, en población pediátrica. Acta Pediatr Mex. 2017;38(2):91-100. DOI: http://dx.doi.org/10.18233/APM38No2pp91-1001360 
to determine the point where preventive therapy should begin, to diagnose active disease and to monitor response to an implanted therapy.

OBJECTIVE: To describe the usefulness of the viral load of CMV in bronchoalveolar lavage (BAL) vs peripheral blood in pediatric patients with signs of respiratory infection.

METHODS: descriptive study, 16 pediatric patients and 19 episodes, which was performed simultaneously CMV viral load in blood and BAL.

RESULTS AND CONCLUSIONS: All viral CMV loads conducted in $\mathrm{BAL}$ were positive and were obtained generally higher values in $\mathrm{BAL}$ that in blood, suggesting a higher sensitivity of the test when it is performed in this sample such shows in patients with clinical suspicion of respiratory infection therefore $\mathrm{CMV}$ becomes an important diagnostic aid as shown by the results obtained.

KEYWORDS: respiratory infection; immunocompromised host; cytomegalovirus; viral load; bronchoalveolar lavage
${ }^{1}$ Hospital Pablo Tobon Uribe, HPTU 1.

${ }^{2}$ Unidad de Investigación genética molecular, UNIGEM, Colombia.

Correspondence

Beatriz Helena Aristizabal baristizabal@hptu.org.co beatriz.aristizabal@unigem.com.co

\section{INTRODUCCIÓN}

Las infecciones pulmonares son comunes en los pacientes inmunocomprometidos. El tipo y número de agentes infecciosos involucrados dependerá de la gravedad del compromiso del sistema inmune. Los individuos con defecto en la respuesta inmune celular son más susceptibles a infecciones oportunistas por microorganismos intracelulares, razón por la que los virus del grupo herpes y virus respiratorios son los agentes etiológicos más frecuentes de infección respiratoria. Los herpesvirus, como los citomegalovirus, generan infecciones latentes que el sistema inmune no puede erradicar. ${ }^{1.2}$

La susceptibilidad a la infección por citomegalovirus es universal. ${ }^{3}$ Es un virus ubicuo geográficamente y tiene alta prevalencia en la población mundial, entre 60 y $70 \%$ en países desarrollados y hasta $100 \%$ en países en vías de desarrollo. ${ }^{4}$
Las infecciones respiratorias por citomegalovirus se ven favorecidas debido a que las células mesenquimales estromales del pulmón tienen una tasa elevada de infección, por lo que detectar la infección respiratoria por citomegalovirus de forma oportuna permite establecer una terapia eficaz y prevenir otras complicaciones. ${ }^{5,6}$

La neumonía causada por citomegalovirus en pacientes trasplantados de médula ósea se ha identificado como una de las principales causas de mortalidad $^{7} y$ tienen mayor susceptibilidad a la infección entre los días 30 a 100 después del trasplante.

La detección del citomegalovirus en líquido de lavado bronquioalveolar permite tener una aproximación al proceso infeccioso el cual, mediante los métodos moleculares, hacen más sensible y oportuna su identificación. ${ }^{2}$

En pacientes inmunocomprometidos la carga viral de citomegalovirus se utiliza de rutina para 
determinar en qué momento se debe iniciar a la terapia preventiva, diagnosticar enfermedad activa y supervisar la repuesta al tratamiento..$^{8-11}$ El tipo de muestra que se requiere para el análisis puede variar según la finalidad de la misma y depende del estado de salud del paciente. ${ }^{12-14}$

La detección del virus se puede realizar en una gran variedad de muestras como sangre, orina y esputo, que no requieren ningún procedimiento invasivo y en otros tipos de muestras que sí requieren procedimientos realizados por profesionales capacitados: extracción de líquidos corporales, biopsias y muestras respiratorias: aspirado traqueal y lavado bronquioalveolar. ${ }^{15}$

Las muestras clínicas habituales para el estudio de citomegalovirus son: suero para la detección de anticuerpos y sangre total para estudios de inmunidad. Para la detección directa por técnicas moleculares se usa una amplia variedad de muestras: sangre, plasma, lavado bronquioalveolar, líquido cefalorraquídeo, tejido, orina y saliva. ${ }^{16}$

La reacción en cadena de la polimerasa (PCR, por sus siglas en inglés) como técnica molecular permite la amplificación de ácidos nucleicos gracias a la acción enzimática de la Taq polimerasa. El empleo de esta técnica como ayuda diagnóstica es muy importante siempre y cuando se tenga una buena estandarización, que incluye desde la toma de la muestra (plasma o sangre total) ${ }^{17-20}$ hasta la realización de la misma para vigilar a los pacientes en el tiempo bajo condiciones controladas de laboratorio. ${ }^{16}$

Utilidad clínica de las cargas virales de citomegalovirus por técnicas moleculares

Típicamente el plasma o la sangre total se usan para realizar las cargas virales de citomegalovirus. El ácido desoxirribonucleico (ADN) de citomegalovirus se detecta más frecuentemente, y en mayores proporciones, en sangre total que en plasma, con niveles tan altos como 10 veces ( $1 \log 10)$ en sangre total, comparado con el plasma; ${ }^{16}$ sin embargo, no siempre se correlacionan las cargas virales bajas en sangre con la enfermedad activa por citomegalovirus. ${ }^{12}$

El empleo de plasma en lugar de sangre total se ha recomendado por su mayor correlación con replicación activa de citomegalovirus, ya que la detección del ADN de citomegalovirus en sangre total puede reflejar solamente la presencia del virus en los linfocitos, donde permanece en estado de latencia tras la infección primaria. ${ }^{21}$ Igualmente, como reflejo de replicación activa y diseminación del virus, algunos trabajos han planteado la controversia entre detección de ADN o detección de ácido ribonucleico mensajero (ARNm), que supone un paso más en la expresión genómica del virus y sólo está presente cuando el virus se está replicando. 22,23

En el recién nacido el $A D N$ de citomegalovirus en muestras de orina, tomadas en las dos primeras semanas de vida, confirma el diagnóstico de infección congénita. ${ }^{24}$ La detección de ADN en sangre, saliva o líquido cefalorraquídeo también es diagnóstica de infección congénita, pero la sensibilidad es menor que en la orina. ${ }^{24}$

A pesar de que muchos trabajos han intentado establecer un punto de corte de la carga viral que sea pronóstico del riesgo de citomegalovirus en el período postrasplante, para instaurar terapia anticipada, hay gran variabilidad de resultados entre técnicas y laboratorios. En muchos casos se recomienda, más que un valor absoluto, determinar la variación durante la supervisión. ${ }^{21-23}$ La experiencia y observación clínica, junto con un adecuado algoritmo de seguimiento acordado entre virólogos y médicos, han permitido en muchos hospitales establecer puntos de corte de la carga viral de citomegalovirus para la instauración de terapia antiviral anticipada. ${ }^{25,26}$ 
Las pruebas moleculares son superiores a la antigenemia debido a la estabilidad de la muestra; requieren menor volumen y no tiene limitaciones en pacientes leucopénicos o con infección asintomática. ${ }^{27-30}$ En pacientes trasplantados de pulmón, la reacción en cadena de la polimerasa cuantitativa se puede realizar en líquido de lavado bronquioalveolar y tiene una sensibilidad mucho mayor al cultivo; sin embargo, un resultado positivo del lavado puede representar una siembra viral o una enfermedad pulmonar ${ }^{31-35}$ y es difícil diferenciar entre una infección asintomática y una invasiva. Algunos estudios han relacionado las cargas virales de citomegalovirus con neumonitis en lavado bronquioalveolar. ${ }^{36,37}$

\section{Carga viral para citomegalovirus en muestras de lavado bronquioalveolar}

Los resultados de la carga viral para citomegalovirus en muestras de lavado bronquioalveolar de pacientes postrasplante pulmonar son divergentes; ${ }^{36}$ es decir, difieren en su utilidad como prueba discriminatoria de neumonitis por citomegalovirus y no permiten identificar a los pacientes con y sin enfermedad por citomegalovirus. ${ }^{37}$ También se observa que algunos pacientes que no desarrollaron enfermedad por citomegalovirus tuvieron episodios espontáneos de cargas virales altas para citomegalovirus en lavado bronquioalveolar y en el seguimiento posterior fueron negativos. ${ }^{15,16}$

Por otra parte, en pacientes trasplantados pulmonares la carga viral de citomegalovirus en lavado bronquioalveolar fue más alta que en sangre y sugiere que su determinación en lavado bronquioalveolar puede ser útil para la detección de individuos en riesgo de desarrollar enfermedad invasiva por citomegalovirus. Además, en los receptores de trasplante pulmonar la carga viral de citomegalovirus positiva, en lavado bronquioalveolar, puede ser más predictiva que la carga viral de citomegalovirus en sangre y más útil que el cultivo celular. ${ }^{38}$
La gran variabilidad en los resultados descritos en la literatura se puede atribuir al uso de diferentes metodologías, diversos blancos genómicos a ser amplificados, al origen de la muestra (líquido vs. células de lavado bronquioalveolar), a los protocolos de inmunosupresión, de terapia preventiva dirigida contra el citomegalovirus post trasplante y a la dificultad de tener un punto de corte para considerar infección, colonización o presencia asintomática del virus. Además, la prueba estándar de oro a comparar que es el cultivo viral, tiene baja sensibilidad y se requiere de un laboratorio especializado para su realización..$^{34,39-41}$

\section{OBJETIVO}

Describir la utilidad de la carga viral de citomegalovirus en lavado bronquioalveolar vs. sangre periférica en la población pediátrica con signos de infección respiratoria, que acuden a un hospital de alta complejidad de la ciudad de Medellín, Colombia.

\section{MATERIALES Y MÉTODOS}

Tipo de estudio: descriptivo observacional.

Población: durante dos años se recolectaron los datos de 16 pacientes a quienes se les realizó simultáneamente carga viral de citomegalovirus en sangre y lavado bronquioalveolar con un total de 19 episodios. Este grupo estaba conformado por nueve niños y siete niñas.

Protocolo de extracción y amplificación: para el procesamiento de la muestra y medición posterior de la carga viral se utilizó un protocolo estandarizado en el laboratorio de Biología Molecular de nuestra institución, que incluyó extracción del ADN por el método de Qiagen y reacción en cadena de la polimerasa en tiempo real de TIB $\mathrm{MOLBIOL}^{\circledR}$ usando el equipo Lightcycler 2.0. Todas las pruebas fueron previamente verificadas. 
Análisis estadístico: se aplicaron estadísticas descriptivas, análisis de regresión y Mann-Whitney. Se consideraron valores significativos de $\mathrm{p}$ por debajo de 0.05.

\section{RESULTADOS Y CONCLUSIONES}

No hubo diferencia en la presentación de la enfermedad de acuerdo al sexo y el promedio de edad en años fue de 7.3 (4 meses-16 años). Para describir la utilidad de la carga viral en lavado bronquioalveolar comparada con la viremia en sangre, se evaluaron las cargas virales en ambos tipos de muestras de la población de estudio, que acudieron a un hospital de alta complejidad de la ciudad de Medellín. Los resultados demuestran que la carga viral fue mayor en lavado bronquioalveolar en pacientes con una enfermedad pulmonar de base, que en pacientes cuya enfermedad de base no tenía como órgano principal el pulmón (84.2\% vs. 15.8\%). El número de copias obtenido en la carga viral del lavado bronquioalveolar en pacientes inmunosuprimidos severos comparado con la carga viral en sangre, permite asociar fuertemente la neumonitis por citomegalovirus y es más predictiva que la carga viral en sangre.

Todas las pruebas realizadas en lavado bronquioalveolar tuvieron una carga viral de citomegalovirus positiva. Llama la atención que la mayoría de individuos con carga viral citomegalovirus positiva en lavado bronquioalveolar tenían sospecha o confirmación de inmunodeficiencia primaria o secundaria $(6 / 16,37.5 \%)$, seguido de malignidades hematológicas $(5 / 16,31.25 \%)$ y post trasplante de órganos sólidos de pulmón o corazón (1/16, $6.25 \%$ ). En el Cuadro 1 se muestran las características de los episodios de estudio.

Los episodios cuatro y cinco corresponden a un mismo paciente en quien la carga viral de citomegalovirus en sangre fue negativa, a pesar de tener un diagnóstico de infección congénita por citomegalovirus; dicha detección fue positiva en lavado bronquioalveolar con una reducción de 0.33 logaritmos después de 21 días del inicio de la terapia.

Los episodios seis y siete corresponden a una paciente con inmunodeficiencia combinada grave con resultado positivo para citomegalovirus en sangre y en lavado bronquioalveolar. A pesar de utilizar una terapia combinada de ganciclovir y foscarnet sólo se logró una reducción de 1.81 logaritmos en el lavado bronquioalveolar, mientras que en sangre incrementó 0.61 logaritmos después de 11 días de tratamiento.

El paciente correspondiente a los episodios 14 y 15 mostró una disminución de la carga viral con el tratamiento, pero no se logró llegar a resultados no detectables y el paciente falleció debido a la suma de otras infecciones que empeoraron su estado.

Se resalta que la condición de inmunocompromiso principal fueron las inmunodeficiencias primarias (Figura 1).

Se consideró un resultado positivo de la carga viral para citomegalovirus un valor $\geq 2,600$ copias/ $\mathrm{mL}$ teniendo en cuenta las recomendaciones del grupo de infectólogos pediatras de la institución. En las cargas virales de citomegalovirus en lavado bronquioalveolar se obtuvo un valor mínimo de 2,656 copias/mL y máximo de 148,000,000 copias/mL con un promedio de 793,378 copias/ $\mathrm{mL}$; y en SP, con resultado positivo, el valor mínimo fue 9,040 copias/mL y máximo 1,256,000 copias/mL con un promedio de 99,023 copias/ $\mathrm{mL}$. Lo cual concuerda con los estudios publicados donde la carga viral para citomegalovirus en lavado bronquioalveolar resulta mayor.

La Figura 2 muestra la comparación del líquido de lavado bronquioalveolar vs. sangre periférica en cada uno de los episodios del estudio. 
Cuadro 1. Características de los pacientes evaluados (Continúa en la siguiente página)

\begin{tabular}{|c|c|c|c|c|c|c|}
\hline Episodio & Género/edad & Diagnóstico de base & $\begin{array}{l}\text { Carga viral CMV en } \\
\text { sangre (copias/mL) }\end{array}$ & $\begin{array}{l}\text { Carga viral CMV en } \\
\text { LBA (copias/mL) }\end{array}$ & $\begin{array}{l}\text { Tratamiento } \\
\text { para CMV }\end{array}$ & $\begin{array}{c}\text { Terapia inmu- } \\
\text { nosupresora }\end{array}$ \\
\hline 1 & Masc/4 años & $\begin{array}{l}\text { Inmunodeficiencia } \\
\text { celular }\end{array}$ & Negativa & 4,544 & G & N.A \\
\hline 2 & Fem/3 años & LLA & Negativa & 2,656 & ND & $\begin{array}{l}\text { Quimio- y } \\
\text { radioterapia }\end{array}$ \\
\hline 3 & $\begin{array}{l}\text { Masc/21 } \\
\text { meses }\end{array}$ & Trasplante hepático & Negativa & 13,200 & G y V & Prednisolona \\
\hline 4 & $\begin{array}{l}\text { Masc/4 } \\
\text { meses }\end{array}$ & $\begin{array}{l}\text { CMV congénita, sos- } \\
\text { pecha de inmunode- } \\
\text { ficiencia }\end{array}$ & Negativa & 13,920 & G & N.A \\
\hline 5 & $\begin{array}{l}\text { Masc/4 } \\
\text { meses }\end{array}$ & $\begin{array}{l}\text { CMV congénita, sos- } \\
\text { pecha de inmunode- } \\
\text { ficiencia }\end{array}$ & Negativa & 6,504 & G & N.A \\
\hline 6 & Fem/7 meses & $\begin{array}{l}\text { Inmunodeficiencia } \\
\text { severa combinada } \\
\text { tipo II, P. jirovecii }\end{array}$ & 107,200 & $1,728.000$ & Gy $F$ & N.A \\
\hline 7 & Fem/7 meses & $\begin{array}{l}\text { Inmunodeficiencia } \\
\text { severa combinada } \\
\text { tipo II, P. jirovecii }\end{array}$ & 43,768 & 26,760 & Gy $F$ & N.A \\
\hline 8 & $\begin{array}{l}\text { Masc/21 } \\
\text { meses }\end{array}$ & $\begin{array}{l}\text { Hemofilia B con in- } \\
\text { hibidores }\end{array}$ & Negativa & 15,120 & No recibió & N.A \\
\hline 9 & Fem/14 años & $\begin{array}{l}\text { Nefropatía lúpica } \\
\text { IV/V , neumonía por } \\
P \text {. jirovecii }\end{array}$ & 28,000 & 26,520 & G y V & $\begin{array}{l}\text { Prednisolona, } \\
\text { ciclofosfami- } \\
\text { da, rituximab }\end{array}$ \\
\hline 10 & Masc/12 años & $\begin{array}{l}\text { POP de estenosis } \\
\text { supravalvular, tetra- } \\
\text { logía de Fallot, des- } \\
\text { nutrición crónica }\end{array}$ & 9,040 & 41,080 & G & N.A \\
\hline 11 & Fem/15 años & LLA & Negativo & 4,616 & No recibió & Quimioterapia \\
\hline 12 & Fem/16 años & $\begin{array}{l}\text { LES, IRC no especi- } \\
\text { ficada }\end{array}$ & Negativo & 17,040 & G & N.A \\
\hline 13 & Masc/10 años & $\begin{array}{l}\text { Linfoma de células } \\
\text { T, No Hodkin me- } \\
\text { diastinal }\end{array}$ & Negativa & 15,560 & G & Quimioterapia \\
\hline 14 & Masc/13 años & $\begin{array}{l}\text { Trasplante de m.o, } \\
\text { leucemia promielo- } \\
\text { cítica, enf. tóxica del } \\
\text { hígado }\end{array}$ & Negativa & 12,000 & G & $\begin{array}{l}\text { Metilpred- } \\
\text { nisolona, } \\
\text { ciclosporina }\end{array}$ \\
\hline 15 & Masc/13 años & $\begin{array}{l}\text { Trasplante de m.o, } \\
\text { leucemia promielo- } \\
\text { cítica, enf. tóxica del } \\
\text { hígado }\end{array}$ & 43,520 & 33,440 & G & $\begin{array}{l}\text { Metilpred- } \\
\text { nisolona, } \\
\text { ciclosporina }\end{array}$ \\
\hline 16 & Fem/14 años & $\begin{array}{l}\text { Síndrome de pul- } \\
\text { món-riñon, hemorrá- } \\
\text { gia alveolar, edema } \\
\text { pulmonar }\end{array}$ & Negativa & 326,400 & G & $\begin{array}{l}\text { Prednisolona, } \\
\text { rituximab }\end{array}$ \\
\hline
\end{tabular}


Cuadro 1. Características de los pacientes evaluados (Continuación)

\begin{tabular}{|c|c|c|c|c|c|c|}
\hline Episodio & Género/edad & Diagnóstico de base & $\begin{array}{l}\text { Carga viral CMV en } \\
\text { sangre (copias/mL) }\end{array}$ & $\begin{array}{l}\text { Carga viral CMV en } \\
\text { LBA (copias } / \mathrm{mL} \text { ) }\end{array}$ & $\begin{array}{l}\text { Tratamiento } \\
\text { para CMV }\end{array}$ & $\begin{array}{c}\text { Terapia inmu- } \\
\text { nosupresora }\end{array}$ \\
\hline 17 & Masc/11 años & $\begin{array}{l}\text { Hidronefrosis congé- } \\
\text { nita, insuf. respirato- } \\
\text { ria aguda, derrame } \\
\text { pleural }\end{array}$ & Negativa & 9,120 & G & $\begin{array}{l}\text { Hidrocorti- } \\
\text { sona, } \\
\text { ciclosporina }\end{array}$ \\
\hline 18 & Fem $/ 6$ meses & $\begin{array}{l}\text { Enfermedad pulmo- } \\
\text { nar intersticial, insuf. } \\
\text { aguda de vías resp. } \\
\text { superiores }\end{array}$ & Negativa & 446,400 & V & N.A \\
\hline 19 & $\begin{array}{l}\text { Masc/11 } \\
\text { meses }\end{array}$ & $\begin{array}{l}\text { Trasplante de m.o, } \\
\text { insuf. resp. aguda, } \\
\text { falla y rechazo de } \\
\text { trasplante }\end{array}$ & $1,256,000$ & $148,000.000$ & $\begin{array}{c}\text { G y F- } \\
\text { CMV-IGIV }\end{array}$ & N.A \\
\hline
\end{tabular}

CMV: citomegalovirus; Masc: masculino; Fem: femenino; N.A: no aplica; N.R: no realizado; LLA: leucemia linfoblástica aguda; VIH: virus de la inmunodeficiencia humana; POP: post operatorio; LBA: lavado bronco alveolar: P. jirovecii: Pneumocystis jirovecii. G: gancilovir; V: valganciclovir; F: foscarnet; ND: no hay datos ; CMV-IGIV): inmunoglobulina CMV; m.o: médula ósea.

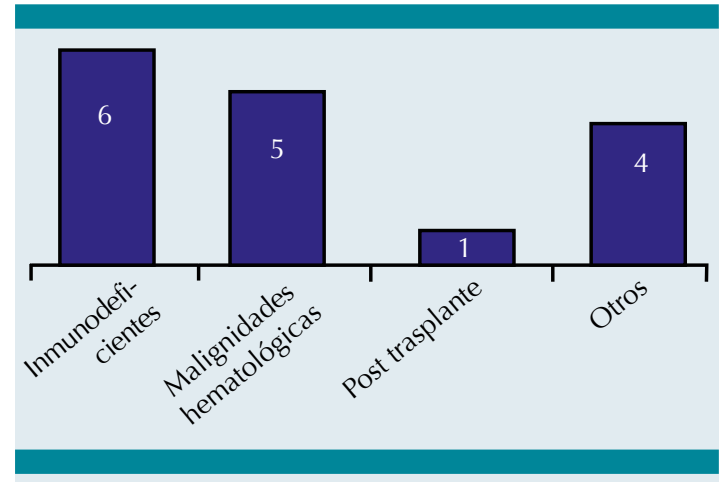

Figura 1. Pacientes con reacción en cadena de la polimerasa positiva en lavado bronquioalveolar de acuerdo a su estado inmunológico.

Como se observa, todas las cargas virales fueron positivas en lavado bronquioalveolar y en 13 de estos episodios no se logró aislar ADN del citomegalovirus en sangre periférica. En las que fueron positivas en ambas muestras, la carga viral en lavado bronquioalveolar fue mucho mayor que las cargas virales en sangre, lo que sugiere que la muestra de lavado bronquioalveolar para carga viral de citomegalovirus es más sensible en pacientes con sospecha clínica de neumonía

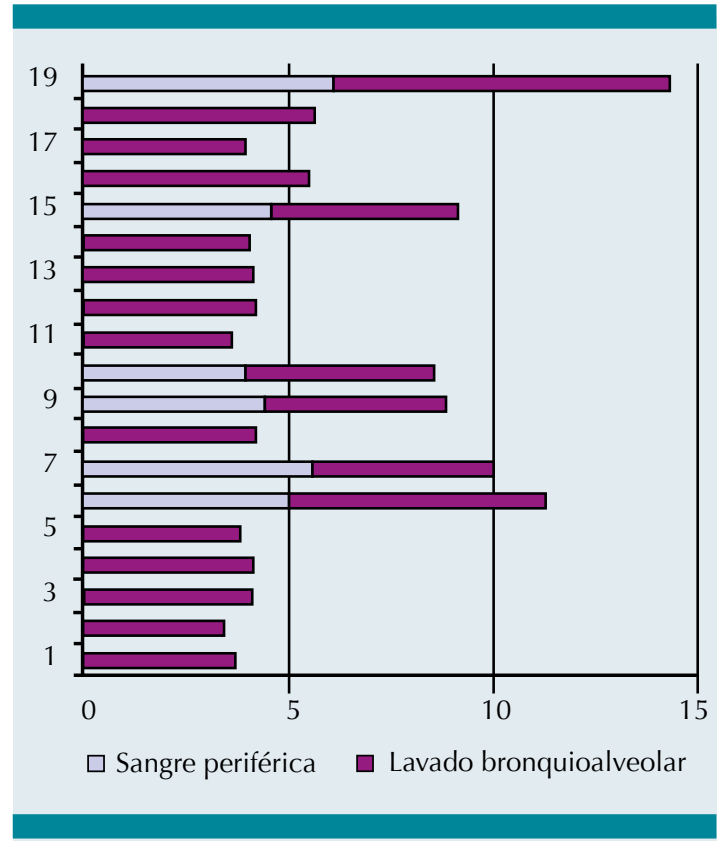

Figura 2. Comparación de las cargas virales para citomegalovirus (Log10) en sangre y lavado bronquioalveolar de acuerdo al número de episodios analizados.

por citomegalovirus a pesar del número bajo de pacientes estudiados. 
La carga viral de citomegalovirus en sangre y lavado bronquioalveolar es una ayuda diagnóstica más rápida, práctica y sensible que los cultivos virales y que la determinación de la antigenemia pp65. 25,27 Sin embargo, las variaciones técnicas como la aplicación de diferentes pruebas moleculares para la medición de la carga viral, los diferentes tipos de reacción en cadena de la polimerasa utilizados (comerciales o in house), los genes blanco de la amplificación, los líquidos corporales en donde se evalúan (plasma, sangre total, lavado bronquioalveolar o biopsia), los puntos de corte (entre otros), hacen difícil la comparación de los resultados entre diferentes estudios y dificultan la interpretación de las pruebas para los pacientes en seguimiento, si se utilizan técnicas diferentes. ${ }^{39}$

Adicionalmente, también existen variables desde el punto de vista médico importantes, ${ }^{4}$ por ejemplo, las enfermedades de base, los diferentes estados de inmunosupresión, las diferentes terapias inmunosupresoras utilizadas y la edad del paciente influyen en el resultado de la carga viral. Así, algunos valores de carga viral pudieran no tener importancia clínica en determinados hospederos pero sí en otros.

Los resultados del trabajo presentan valores superiores de la carga viral para citomegalovirus en las muestras del lavado bronquioalveolar comparado con la sangre periférica, siendo similares a los reportados en la literatura. ${ }^{9-11}$ En el caso de carga viral de citomegalovirus en lavado bronquioalveolar las limitaciones son similares a las encontradas en las pruebas en sangre. ${ }^{11,12}$ La carga viral para citomegalovirus en lavado bronquioalveolar aparece como una adecuada herramienta en pacientes inmunocomprometidos, especialmente en trasplantados, para el diagnóstico y seguimiento de infección, así como la aplicación del tratamiento antiviral. . 15,35,37 $^{2}$

A pesar del bajo tamaño de la muestra utilizada en el presente estudio, y teniendo en cuenta que su comportamiento fue similar a otros estudios con mayor número de muestras incluidas, se podrían sugerir algunas recomendaciones generales al momento de la solicitud de carga viral de citomegalovirus en muestras de lavado bronquioalveolar y tener presente que el diagnóstico de la neumonitis por citomegalovirus es complejo y que no siempre una carga viral en lavado bronquioalveolar positiva significa enfermedad activa:

1. El médico debe conocer las indicaciones de la carga viral de citomegalovirus en lavado bronquioalveolar.

2. Se deben optimizar al máximo las muestras de lavado bronquioalveolar puesto que son muestras valiosas e invasivas.

3. Es ideal siempre ordenar de manera simultánea carga viral en lavado bronquioalveolar y plasma.

4. Interpretar los resultados siempre considerando el contexto clínico del paciente y otras ayudas diagnósticas como las imágenes radiológicas.

5. Por su alta sensibilidad, un resultado negativo de una carga viral de citomegalovirus en lavado bronquioalveolar por reacción en cadena de la polimerasa en tiempo real tiene un alto valor predictivo negativo.

6. Debido a la alta sensibilidad de las pruebas moleculares quien realiza el diagnóstico finalmente es el clínico, teniendo en cuenta el contexto del paciente y las ayudas diagnósticas utilizadas.

Es importante considerar el seguimiento del paciente mediante la realización de la carga viral siguiendo los protocolos internacionales; es decir, la carga viral se debe realizar en un mismo sitio, bajo una misma técnica y con el mismo tipo de muestra para poder comparar 
y hacer seguimiento adecuado y definir, si es del caso, el inicio o no de terapia antiviral. La carga viral de citomegalovirus en muestras de lavado bronquioalveolar es un recurso útil en el diagnóstico de la neumonía por citomegalovirus en pacientes pediátricos, como lo muestran los resultados obtenidos. ${ }^{15,37}$

\section{REFERENCIAS}

1. Snydman DR, Limaye AP, Potena L, Zamora MR. Update and review: state-of-the-art management of cytomegalovirus infection and disease following thoracic organ transplantation. Transplant Proc. 2011;43(3 Suppl):S1-S17.

2. Schlischewsky E, Fuehner T, WRNAecke G, Welte T, Haverich A, Ganzenmueller T, Heim A, Gottlieb J. Clinical significance of quantitative cytomegalovirus detection in bronchoalveolar lavage fluid in lung transplant recipients. Transpl Infect Dis. 2013;15:60-69.

3. Agut $\mathrm{H}$, Bonnafous $\mathrm{P}$, Gautheret-Dejean $\mathrm{A}$, Laboratory and clinical aspects of human herpesvirus 6 infections. Clin Microbiol Rev. 2015;28(2):313-35.

4. Vilibic-Cavlek T, Kolaric B, Ljubin-Sternak S, Kos M, Kaic B, Mlinaric-Galinovic G. Prevalence and dynamics of cytomegalovirus infection among patients undergoing chronic hemodialysis. Indian J Nephrol. 2015;25(2):95-8.

5. Hodson EM, Craig JC, Strippoli GF, Webster AC. Antiviral medications for preventing cytomegalovirus disease in solid organ transplant recipients. Cochrane Database Syst Rev. 2013 Feb 28;2:CD003774. doi: 10.1002/14651858. CD003774.

6. Drew WL. Laboratory diagnosis of cytomegalovirus infection and disease in immunocompromised patients. Curr Opin Infect Dis. 2007;20(4):408-411.

7. Travi $\mathrm{G}$ and Pergam S.A. Cytomegalovirus Pneumonia in Hematopoietic Stem Cell Recipients. J Intensive Care Med. 2014;29(4):200-12.

8. Aitken C, Barrett-Muir W, Millar C, et al. Use of molecular assays in diagnosis and monitoring of cytomegalovirus disease following renal transplantation. J Clin Microbiol. 1999;37(9):2804-7.

9. Kraft CS, Armstrong WS, Caliendo AM. Interpreting quantitative cytomegalovirus DNA testing: understanding the laboratory perspective. Clin Infect Dis. 2012;54(12):1793-7.

10. Tong $C Y$, Cuevas $L E$, Williams $H$, Bakran A. Comparison of two commercial methods for measurement of cytomegalovirus load in blood samples after renal transplantation. J Clin Microbiol. 2000;38(3):1209-13.

11. Humar A, Gregson D, Caliendo AM, et al. Clinical utility of quantitative cytomegalovirus viral load determination for predicting cytomegalovirus disease in liver transplant recipients. Transplantation.1999;68(9):1305-11.
12. Razonable RR, Brown RA, Wilson J, et al. The clinical use of various blood compartments for cytomegalovirus (CMV) DNA quantitation in transplant recipients with CMV disease. Transplantation. 2002;73(6):968-73.

13. Engelmann I, Petzold DR, Kosinska A, Hepkema BG, Schulz TF, Heim A. Rapid quantitative PCR assays for the simultaneous detection of herpes simplex virus, varicella zoster virus, cytomegalovirus, Epstein-Barr virus, and human herpesvirus 6 DNA in blood and other clinical specimens. J Med Virol. 2008;80(3):467-477.

14. Abdul-Ali D, Kraft CS, Ingersoll J, et al. Cytomegalovirus DNA stability in EDTA anti-coagulated whole blood and plasma samples. J Clin Virol. 2011;52(3):222-4.

15. Chemaly RF, Yen-Lieberman B, Chapman J, et al. Clinical utility of cytomegalovirus viral load in bronchoalveolar lavage in lung transplant recipients. Am J Transplant. 2005;5(3):544-548.

16. Lisboa LF, Asberg A, Kumar D, et al. The clinical utility of whole blood versus plasma cytomegalovirus viral load assays for monitoring therapeutic response. Transplantation. 2011;91(2):231-6.

17. Kerschner $H$, Bauer $C$, Schlag $P$, et al. Clinical evaluation of a fully automated CMV PCR assay. J Clin Virol. 2011;50(4):281-6.

18. Caliendo AM, Ingersoll J, Fox-Canale AM, et al. Evaluation of real-time PCR laboratory-developed tests using analytespecific reagents for cytomegalovirus quantification. J Clin Microbiol. 2007;45(6):1723-7.

19. Caliendo AM, Yen-Lieberman B, Baptista J, et al. Comparison of molecular tests for detection and quantification of cell-associated cytomegalovirus DNA. J Clin Microbiol. 2003;41(8):3509-13.

20. Caliendo AM, St George K, Allega J, et al. Distinguishing cytomegalovirus (CMV) infection and disease with CMV nucleic acid assays. J Clin Microbiol. 2002;40(5):1581-6.

21. KulkRNAi A, Westmoreland D, Fox JD. Molecular-based strategies for assessment of CMV infection and disease in immunosuppressed transplant recipients. Clin Microbiol Infect. 2001;7(4):179-86

22. Humar A, Kumar D, Boivin G, Caliendo AM. Cytomegalovirus (CMV) virus load kinetics to predict recurrent disease in solid-organ transplant patients with CMV disease. J Infect Dis. 2002;186(6):829-33.

23. Gerna G, Baldanti F, Lilleri D, Parea M, Alessandrino E, Pagani $A$, et al. Human cytomegalovirus immediateearly mRNA detection by nucleic acid sequence based amplification as a new parameter for preemptive therapy in bone marrow transplant recipients. J Clin Microbiol. 2000;38(5):1845-53.

24. Revello MG, Gerna G. Diagnosis and management of human cytomegalovirus infection in the mother, fetus, and newborn infant. Clin Microbiol Rev. 2002;15(4):680-715.

25. Weinberg A, Hodges TN, Li S, et al. Comparison of PCR, antigenemia assay, and rapid blood culture for detection 
and prevention of cytomegalovirus disease after lung transplantation. J Clin Microbiol. 2000;38(2):768-72.

26. Hassan-Walker AF, Kidd IM, Sabin C, et al. Quantity of human cytomegalovirus (CMV) DNAemia as a risk factor for CMV disease in renal allograft recipients: relationship with donor/recipient CMV serostatus, receipt of augmented methylprednisolone and antithymocyte globulin (ATG). J Med Virol. 1999;58(2):182-7.

27. Caliendo AM, St George K, Kao SY, et al. Comparison of quantitative cytomegalovirus (CMV) PCR in plasma and $\mathrm{CMV}$ antigenemia assay: clinical utility of the prototype AMPLICOR CMV MONITOR test in transplant recipients. J Clin Microbiol. 2000;38(6):2122-7.

28. Kerschner $\mathrm{H}$, Bauer $\mathrm{C}$, Schlag $\mathrm{P}$, et al. Clinical evaluation of a fully automated CMV PCR assay. J Clin Virol. 2011;50(4):281-6.

29. Schäfer P, Tenschert W, Gutensohn K, Laufs R. Minimal effect of delayed sample processing on results of quantitative PCR for cytomegalovirus DNA in leukocytes compared to results of an antigenemia assay. J Clin Microbiol. 1997;35(3):741-4.

30. Abdul-Ali D, Kraft CS, Ingersoll J, et al. Cytomegalovirus DNA stability in EDTA anti-coagulated whole blood and plasma samples. J Clin Virol. 2011;52(3):222-4.

31. Razonable RR, Brown RA, Espy MJ, et al. Comparative quantitation of cytomegalovirus (CMV) DNA in solid organ transplant recipients with $\mathrm{CMV}$ infection by using two high-throughput automated systems. J Clin Microbiol. 2001;39(12):4472-6.

32. Smith TF, Espy MJ, Mandrekar J, et al. Quantitative realtime polymerase chain reaction for evaluating DNAemia due to cytomegalovirus, Epstein-Barr virus, and BK virus in solid-organ transplant recipients. Clin Infect Dis. 2007;45:1056-61.

33. Ferreira-Gonzalez A, Fisher RA, Weymouth LA, et al. Clinical utility of a quantitative polymerase chain reaction for diag- nosis of cytomegalovirus disease in solid organ transplant patients. Transplantation. 1999;68(7):991-6.

34. Sia IG, Wilson JA, Groettum CM, et al. Cytomegalovirus (CMV) DNA load predicts relapsing CMV infection after solid organ transplantation. J Infect Dis. 2000;181:717-20.

35. Razonable RR, Brown RA, Wilson J, et al. The clinical use of various blood compartments for cytomegalovirus (CMV) DNA quantitation in transplant recipients with CMV disease. Transplantation. 2002;73:968-73.

36. Costa C, Curtoni A, Sidoti F, Balloco C, Simeone S, Mantovani S, Piasentin Alessio E, Libertucci D, Delsedime L, Solidoro P, Baldi S, Cavallo R.Detection of human cytomegalovirus in transbronchial biopsies from lung transplant recipients. Arch Virol. 2013;158(7):1461-5.

37. Costa $C$, Delsedime L, Solidoro P, Curtoni A, Bergallo M, Libertucci D, Baldi S, Rinaldi M, Cavallo R. Herpesviruses detection by quantitative real-time polymerase chain reaction inbronchoalveolar lavage and transbronchial biopsy in lung transplant: viral infections and histopathological correlation. Transplant Proc. 2010;42(4):1270-4.

38. Jouneau S, Poineuf JS, Minjolle S, Tattevin P, Uhel F, Kerjouan M, Le Hô H, Desrues B.Which patients should be tested for viruses on bronchoalveolar lavage fluid? Eur J Clin Microbiol Infect Dis. 2013;32(5):671-7.

39. Pang XL, Fox JD, Fenton JM, et al. Interlaboratory comparison of cytomegalovirus viral load assays. Am J Transplant. 2009;9:258-68.

40. Wiita AP, Roubinian N, Khan Y, Chin-Hong PV, Singer JP, Golden $J A$, Miller S. Cytomegalovirus disease and infection in lung transplant recipients in the setting of planned indefinite valganciclovir prophylaxis. Transpl Infect Dis. 2012;14(3):248-58.

41. Henke-Gendo C, Ganzenmueller T, Kluba J, Harste G, Raggub L, Heim A. Improved quantitative PCR protocols for adenovirus and $\mathrm{CMV}$ with an internal inhibition control system and automated nucleic acid isolation. J Med Virol. 2012;84(6):890-896. 